\title{
Policy in Relation with Health of Citizens
}

\author{
Burim Beqiri \\ Arian Musliu \\ Genc Rexhepi
}

Heimerer College

\begin{abstract}
Policy is a key factor of development and demolition of a particular country, especially Kosovo as a new country in the region. Studies showed that there is a link between economic policy, inequality and health of the population. One of the biggest surprises in the literature and studies in Europe and America is that there are few studies on policy variables and their impact on health and income. Health is the main factor, affecting the social and the welfare, also lack of health come as a result of political factors (Vincent Navarro, 2008). Rudolf Virchow stated that "Medicine is a social science while politic is nothing except the high-level medicine". The biggest development in the political field, were done by avoiding affects, welfare and directly affects health of citizens (Navarro V., 2000). Recently there were too many changes in governments confusing population so we wanted to study the current policy and to clarify if policy is a factor that affects health. Participants in this research were 86 citizens (64 percent males) in five cities of Kosovo chosen systematically sample. We used four questionnaires: Self-created questionnaires to measure the current state of the political based on two other questionnaires, we used Ault Hope Scale (AHS) (Snyder C. R., et. Al., 1991) to measure hope, Centre for Epidemiological Studies Depression Scale (CES-DS) (Radloff,, 1977) to measure situation of current depression in general population and The Satisfaction with Life Scale (SwLS) (Diener et al., 1985) to measure satisfaction. (Data were analyzed using the statistical Package for social science (SPSS, 22). Results show that citizens are disappointed by the current political situation in Kosovo (72.5 percent). Also 73.2 percent of the respondents accepted that they are too agitated to recent political events, which consequently follows that 47.2 percent of them have been depressed. These studies show that political situation is an indicator factor in health and wellbeing of citizens directly, or indirectly by increasing the scale of depression and anxiety. Policy is the main discussion topic in society and also in family so there is plenty of space to study the current policy and the effects on social wellbeing..
\end{abstract}

Keywords: Political beliefs, health, wellbeing, empirical evidence.

\section{Political Beliefs, Wellbeing, Hope and Satisfaction with Life}

Countries develop policies in order to create a deliberate system to guide decisions and achieve rational outcomes. These policies are often developed to be implemented as protocols or procedures. The reason behind this is to assist both subjective and objective decision-making of the population in general (University of Sidney, 2016). In this direction, health policies are also developed and implemented. According to the University of Sidney (2016), these policies are often presented in public as a discussion regarding the health system issues and aim to enhance research and decision making in order to produce better services and qualitative health care. That being said, health is considered as the main factor affecting social life and wellbeing. However, the lack of health among a population is often a result of bad political decisions in specific countries (Navarro et al., 2006). In turn, as wellbeing is directly affected, living in that country does not satisfy the necessary needs. In other words, the wellbeing of an individual's life and all its aspects is affected the most (Diener et. al., 2009). Wellbeing, however, can be subjective and objective. Summer (1996) showed that subjective wellbeing is related to an individual's preferences, needs and desires while objective wellbeing is usually related to social, mental and physical health. Further, Summer (1996) also showed that there is a relationship between wellbeing and policies. This suggests a direct relationship of policies with the economy, which in turn is related to general wellbeing and health. Health in terms of 
policies is usually referred to as medicine. That is why people usually say that policies are nothing more than high-level medicine. Thus, as argued above, most of the policies are directed towards the development of medicine, which increases wellbeing and health (Navarro \& Shi, 2001). However, policies are not always directed only towards medicine. Happiness is also an outcome of good policies.

That is why Layard (2006) studied happiness and the causes of happiness. Layard argues that when you ask people what makes them happy, the answer is usually money. This yielded in researching happiness and income. The latter is usually an outcome of the policies. He came up with the results that money and income status make people happier. Layard (2006) argues that this is in line with other studies which also suggest a positive relationship between economical status and income (Pen \& Tinbergen, 1977; Sen, 1997). However, Easterlin (1974) does not suggest the same pattern. He suggests that the relationship is not linear but curvilinear. That being said, the wealth of nations and average happiness are related, but not with poverty in an absolute sense. Likewise, no linear relationship was found from Bjørnskov, Drehe, and Fischer (2007) and Fahey and Smyth (2003). The findings however are very mixed. That is because Berg and Veenhoven (2010) found a relationship between policies and wealthiness which indirectly affects the happiness of a population. The interesting part is that there are no significant differences between countries. This means that people are used to living with the income they already have and are happy enough.

\section{Aim of the Study and Hypotheses}

As we already know that there is a relationship between policies and wellbeing indirectly, and we do have some positive results, the current study aims to check whether the perception regarding the political situation affects the general depression of a population and their happiness. Thus, three hypotheses were developed, however, we do not specify the direction of the relationship because we believe that this depends on the positive or negative perception regarding the current political state.

H1: Perception regarding political state affects depression.

$\mathrm{H} 2$ : Current political state impacts satisfaction.

H3: Current political state also impacts hope.

\section{Methodology}

\section{Sample}

Participants in this research were 86 citizens (64\% males) which were selected based on the random formula. Thus, one participant from every third house in each of the five cities in Kosovo was selected. Around $40.7 \%$ of the participants did finish their high school and on average participants reported their health state as good.

\section{Instruments}

We used four questionnaires: (1) a self-created questionnaire to measure the current beliefs regarding the actual political state, (2) Adult Hope Scale (AHS; Snyder et al., 1991) to measure hope, (3) Centre for Epidemiological Studies-Depression Scale (CES-DS; Radloff, 1977) to measure current depression in the general population, and (4) the Satisfaction with Life Scale (SwLS; Diener et al., 1985) to measure satisfaction with life.

\section{Procedure}

This research project was designed to achieve our objective as accurately as possible and all the risks were considered. Then, we started collecting the data in the field. We asked for permission from every person we selected to participate in the study prior to completing the questionnaires. The questionnaires were self-administrated and the time it took to complete all the questions was 15-20 minutes. We made sure that participants did not forget any of the questions because every non-complete question would doubt the reliability of the study. The same procedure was used by all five researchers engaged in this project from five cities of Kosovo. Lastly, the data was analyzed and the hypotheses were tested.

\section{Results}

Below you will find the main findings of this study. All the analyses were correlation analyses due to the cross-sectional design of this study. Thus, we tested each of the hypotheses aforementioned. 


\section{Fast Facts}

$14.0 \%$ were disappointed with the way the actual government leads.

$39.5 \%$ thought that there is hope and that life in Kosovo will get better.

$81.5 \%$ were frustrated about the current political state in Kosovo.

$73.2 \%$ were concerned about recent political events.

$58.1 \%$ thought that the political state is not getting any better.

$57 \%$ thought that compering the political state before 2008 right now we stand much better.

$61.6 \%$ of people don't think that they have the strength and power to change anything in the current political state.

$54.6 \%$ were convinced that the future will be better than the present in Kosovo.

$59.3 \%$ consider that corruption is one of the biggest lacks in the current policies.

$44.2 \%$ were worried every day about the current political state.

\section{Main Results}

Results showed that participants were satisfied with life more than average $(M=19.10, S D=5.25)$. Similar findings were found regarding hope $(M=30.73, S D=7.50)$ and depression $(M=30.30, S D=4.99)$.

Table 1.

Descriptive Results of Satisfaction with Life, Hope and Depression

\begin{tabular}{llllll}
\hline & $n$ & Min & Max & $M$ & $S D$ \\
\hline Satisfaction with Life & 86 & 8.00 & 31.00 & 19.10 & 5.25 \\
Hope & 86 & 18.00 & 52.00 & 30.73 & 7.50 \\
Depression & 86 & 19.00 & 46.00 & 30.30 & 4.99 \\
\hline
\end{tabular}

Results presented in Table 2 showed that there is a positive correlation between depression and hope $(r=.137, p=.013)$. However, no significant correlations were found between depression and satisfaction with life, and hope with satisfaction with life.

Table 2

Correlations among Depression, Hope and Satisfaction with Life

\begin{tabular}{llll}
\hline Variables & 1 & 2 & 3 \\
\hline 1. Depression & $/$ & & \\
2. Hope & $.137^{*}$ & $/$ & \\
3. Satisfaction with Life & .098 & .089 & $/$ \\
\hline
\end{tabular}

Further, results showed that there are positive correlations between debates regarding politics in different situations. Please refer to Table 3 for the full list of correlations.

Table 3

Correlations among the Debates Conducted in Different Situations 


\begin{tabular}{llll}
\hline Variables & 1 & 2 & 3 \\
\hline 1. Debate regarding politics in family & 1 & & \\
2. Debate regarding politics in the workplace & $.537^{* *}$ & $/$ & \\
3. Debate regarding politics during the free time & $.669^{* *}$ & $.737^{* *}$ & 1 \\
\hline
\end{tabular}

\section{Discussion}

This study aimed to provide context-based empirical evidence regarding the relationship between political beliefs in terms of the current perceived political situation. Thus, we measured depression, hope, satisfaction with life and the opinions of participants regarding the actual political state. Based on this study we have come to some conclusions that support the literature regarding the indirect impact of policies on our wellbeing and everyday life. Our results showed that there is not a direct relationship between the current political beliefs and satisfaction with life. However, we found a positive relationship between depression and political beliefs. That being said, we can assume that depression is related to wellbeing. Thus, political beliefs are related to wellbeing as well. This provides some kind of support for hypothesis 1 . However, we did not find support for hypotheses 2 and 3 . That is because we did not find a direct significant relationship regarding the relationships between the current political beliefs, satisfaction with life and hope. However, we do not have enough evidence considering this study's limitations to conclude that these relationships do not exist. Previous evidence suggests that hope, depression, satisfaction with life and political beliefs are related directly or indirectly. Thus, these results should be interpreted with caution.

Further, almost half of the participants showed that there are worried regarding the political state in which we were at the moment. In addition, political debates are part of their everyday life, and this could be due to their worry regarding the actual situation. Although this could be the case, the more participants talk about politics in different situations, it transfers also to other situations such as during work or during free time. This, however, does not mean that political discussions are their main topics.

\section{Conclusions and Recommendations}

Based on the results we conclude that political beliefs are indicators in many ways, but not directly in satisfaction with life and hope. However, political beliefs are found to be related to depression, which may be an indicator that wellbeing is affected. Also, we conclude that political debates are part of our debates in our everyday life.

We recommend further research regarding political beliefs and mental health factors. So different studies regarding the relationship between political beliefs, social life, economy, income, wellbeing, satisfaction with life and other factors are necessary to generalize these findings.

\section{References}

[1] Berg, M. C., \& Veenhoven, R. (2010). Income inequality and happiness in 119 nations. In search for an optimum that does not appear to exist.

[2] Bjørnskov, C., Drehe, A., \& Fischer, J. A. (2008). On decentralization and life satisfaction. Economics Letters, 99(1), 147-151.

[3] Diener, E. (1984). Subjective well-being. Psychological bulletin, 95(3), 542.

[4] Easterlin, R. A. (1974). Does economic growth improve the human lot? Some empirical evidence. Nations and households in economic growth, 89, 89-125.

[5] Ed Diener, Richard E. Lucas, Ulrich Schimmack \& John F. Helliwell (2009), Well-being for Public Policy; Oxford University Press

[6] Fahey, T., \& Smyth, E. (2003). What can subjective indicators tell us about inequalities in welfare? Evidence from 33 European societies. Working paper, Dublin, Economic and Social Research Institute. 
[7] Layard, R. (2006), Happiness and Public Policy: a Challenge to the Profession*. The Economic Journal, 116: C24-C33

[8] Navarro, V., \& Shi, L. (2001). The political context of social inequalities and health. Social science \& medicine, 52(3), 481-491.

[9] Navarro, V., Muntaner, C., Borrell, C., Benach, J., Quiroga, Á., Rodríguez-Sanz, M., ... \& Pasarín, M. I. (2006). Politics and health outcomes. The Lancet, 368(9540), 1033-1037.

[10] Pen, J., \& Tinbergen, J. (1977). Naar een rechtvaardiger inkomensverdeling. Elsevier.

[11] Radloff, L. S. (1977). The CES-D scale: A self-report depression scale for research in the general population. Applied Psychological Measurement, 1, 385-401.

[12] Sen, A. (1997). Choice, welfare and measurement. Harvard University Press.

[13] Snyder, C. R., Harris, C., Anderson, J. R., Holleran, S. A., Irving, L. M., Sigmon, S. T., ... \& Harney, P. (1991). The will and the ways: development and validation of an individual-differences measure of hope. Journal of personality and social psychology, 60(4), 570. 